https://doi.org/10.52058/2786-5274-2021-2(2)-144-151

Пшинка Ганна Василівна доцент, кандидат філософських наук, доцент кафедри менеджменту культури та соціальних технологій, Харківська державна академія культури, Бурсацький узвіз, 3, 5-й корпус, кімната 14, м. Харків, 61057, тел.: (050) 975-28-28, e-mail: my_academy@ukr.net, https://orcid.org/0000-00024737-9471

Гетьман Лариса Геннадіївна доцент, кандидат економічних наук, доцент кафедри менеджменту культури та соціальних технологій, Харківська державна академія культури, Бурсацький узвіз, 3, 5-й корпус, кімната 14, м. Харків, 61057, тел.: (050) 661-90-81, e-mail: my_academy@ukr.net, https://orcid.org/0000-00017196-0656

\title{
ВИКОРИСТАННЯ МАРКЕТИНГОВИХ ТЕХНОЛОГІЙ В СУЧАСНОМУ РІТЕЙЛІ
}

Анотація. У статті досліджено підходи до маркетингового моделювання як інструменту, що дозволяє інтегрувати маркетингову концепцію на всі рівні управління підприємства. Досліджено актуальні підходи до бізнес моделювання, суть яких полягає у виявленні таких значущих для бізнесу та маркетингового управління категорій як цільові клієнти, ціннісна пропозиція, структура витрат і механізм отримання виручки. Найбільш перспективний підхід до моделювання маркетингового управління будується на інтеграції сукупності бізнес-процесів і відповідних їм інструментів в загальну бізнесмодель торгового підприємства. Моделі інтегрованого та холістичного маркетингу вважаються найбільш перспективними для формування маркетингової моделі інноваційного розвитку торгівлі, що забезпечує високий рівень клієнтоорієнтованості, залучення споживачів, маркетингового капіталу знань, IT-активів. Загальний підхід до моделювання маркетингової моделі інноваційного розвитку може бути представлений у вигляді єдності компонентів: стратегія інноваційного розвитку, методи маркетингового управління, ресурсне забезпечення. Інтегрована модель маркетингового управління інноваційним розвитком рітейлу, охоплюючи бізнеспроцеси торгового підприємства всіх рівнів, дозволить досягти цілей інноваційного розвитку за рахунок можливості формування взаємовідносин торговельних підприємств з виробниками і споживачами, реалізації маркетингу співтворчості, внутрішнього маркетингу ритейлерів, і забезпечити реалізацію інтересів усіх позначених учасників товарного обігу. Високий рівень інтеграції маркетингової платформи дозволить досягати завдань інноваційного розвитку торгового підприємства за рахунок організаційно-управлінських ресурсів. 


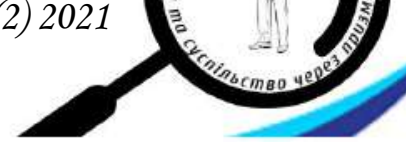

Ключові слова: маркетинг; управління торгівлею; роздрібна торгівля; інноваційний розвиток; методологія.

Pshynka Hanna Vasylivna Associate professor, Ph.D.in Philosophy, associate professor in the Department of Culture Management and Social Technologies, Kharkiv State Academy of Culture, Bursatskyi uzviz, 3, 5th building, room 14, Kharkiv, 61057, tel.: (050) 975-28-28, e-mail: my_academy@ukr.net, https://orcid.org/0000-0002-4737-9471

Getman Larysa Hennadiyivna Associate professor, Ph.D.in Economic, associate professor in the Department of Culture Management and Social Technologies, Kharkiv State Academy of Culture, Bursatskyi uzviz, 3, 5th building, room 14, Kharkiv, 61057, tel.: (050) 661-90-81, e-mail: my_academy@ukr.net, https://orcid.org/0000-0001-7196-0656

\section{USE OF MARKETING TECHNOLOGIES IN MODERN RETAIL}

Abstract. The article investigates approaches to marketing modeling as a tool to integrate the marketing concept at all levels of enterprise management. The actual approaches to business modeling, the essence of which is to identify so important categories for business and marketing management as target customers, value proposition, cost structure and revenue generation mechanism are explored. The most promising approach to modeling of marketing management is based on the integration of a set of business processes and related their tools into the overall business model of the trading enterprise. Models of integrated and holistic marketing are the most promising for the formation of a marketing model of innovative trade's development, as providing a high level of customer focus, customer involvement, marketing knowledge capital, IT -assets. The general approach to modeling of the marketing model of innovative development can be presented in the form of unity of components: strategy of innovative development, methods of marketing management, resource support. The integrated model of marketing management of innovative development of trade, covering business processes of the trade enterprise of all levels, will allow to achieve the purposes of innovative development due to possibility of formation of relationship of the trade enterprises with producers and consumers, realization of marketing of cocreation, internal marketing of retailers, to provide realization of interests of all designated participants of the commodity address. The high level of integration of the marketing platform will allow to achieve the objectives of innovative development of the trading enterprise at the expense of organizational management resources.

Keywords: marketing; trade management; retail; innovative development; methodology. 
Постановка проблеми. Високий рівень конкуренції в торгівлі стимулює впровадження інновацій в організацію рітейл процесу. Маркетингові технології дозволяють розробляти унікальні торгові пропозиції, орієнтовані на покупців 3 різним особистим рівнем доходів і вектором споживання [1]. Забезпечення інноваційного розвитку торгівлі за рахунок маркетингового управління обумовлено специфікою організації торгівлі, особливостями ресурсного забезпечення та формування інноваційного потенціалу. Інновації в торгівлі, як правило, пов'язані з покращенням уже існуючої послуги, стосуються рітейлових нововведень, при цьому високе значення мають маркетингові інновації, так споживач отримує можливість впливати на виробника опосередковано, через торгівлю. Слід враховувати вплив великих торгових компаній, які є флагманом інноваційного розвитку галузі. Для рітейлу характерна поява інновацій, які формуються як в самій торгівлі, так i в суміжних галузях, насамперед у виробництві [2]. Результатом реалізації інноваційного управління будуть: поява додаткової цінності послуги для кінцевих споживачів; підвищення ефективності технології рітейл-процесу; підвищення ефективності конкурентної боротьби; більш повне задоволення запитів споживачів; поява нових форматів, форм, методів і технологій торгівлі; підвищення якості товарів, розширення асортименту [4].

Аналіз останніх досліджень і публікацій. Бізнесмоделювання активно досліджується українськими та зарубіжними вченими та бізнеспрактиками. Однією з помітних робіт в області побудови бізнесмоделі, на наш погляд, можна вважати модель Остервальдер-Піньє. Розробка «канви», як практичного інструменту реалізації бізнеспланування, ініціювала інтерес до бізнесмоделювання, його результатами 3 боку дослідників i практиків. Співробітниками Університету СанктГаллена запропонований навігатор по бізнесмоделям в формі книги «Бізнесмоделі: 55 кращих шаблонів» [5]. Загальна модель, запропонована авторами, перегукується 3 моделлю «канва» і передбачає відповіді на ключові питання про цільових клієнтів, ціннісну пропозицію, ланцюг створення вартості, структуру витрат і механізм генерування виручки. Автори доводять, що для забезпечення конкурентоспроможності в майбутньому недостатньо розробляти нові товари, удосконалювати бізнес-процеси, необхідно оновлювати бізнес моделі, формуючи додатковий інноваційний потенціал.

Мета статті - дослідження різноманіття підходів до побудови маркетингового управління рітейлом, виявлення напрямів формування маркетингової моделі інноваційного розвитку торговельних підприємств.

Виклад основного матеріалу. Вивченню маркетингових моделей, як актуального інструментарію ефективного управління присвячені праці таких вітчизняних вчених, як А. В. Федорченко, С.I. Данило, О.В. Зозульов які одними 3 перших розглядали дану дефініцію. У публікації автори визначили термін «маркетингова модель» як розвиток концепції ринкової орієнтації, виявили етапи 
становлення маркетингових моделей у взаємозв'язку 3 макроекономічним середовищем $[6,7,8]$.

Т.О. Царьова в своєму дослідженні визначає шість основних маркетингових моделей: латентну, раннього іміджевого маркетингу, тактичного неінтегрованого, тактичного частково інтегрованого, стратегічного частково інтегрованого та інтегрованого (холістичного) маркетингу, класифікувавши маркетингові бізнеспроцеси за трьома рівнями - корпоративному, діловому (міжфункціональні) i функціональному [8]. Найбільший інтерес для формування маркетингової моделі інноваційного розвитку торгівлі представляють моделі стратегічного частково інтегрованого та холістичного маркетингу. Ці моделі видаються найбільш перспективними для формування маркетингової моделі інноваційного розвитку торгівлі, як такі що забезпечують високий рівень клієнтоорієнтованості, залучення споживачів, маркетинговогокапіталу знань, IT-активи.

Варто відзначити, що найбільш поширеною в практичній реалізації на сучасному етапі розвитку української роздрібної торгівлі є модель тактичного частково інтегрованого маркетингу. Рівень розвитку клієнтоорієнтованої культури в такій моделі вище середнього, існують стандарти обслуговування. Маркетингу відведена тактична роль. Інтегрована маркетингова платформа реалізується на достатньому, але невисокому рівні, і складається із загальних баз даних, єдиної CRM-системи, спеціалізованого маркетингового програмного забезпечення.

Значний внесок у моделювання інноваційного розвитку рітейлу вніс О.В. Зозульов, розробивши концептуальні засади інноваційної моделі сталого розвитку торгівлі на основі ресурсообміну. Такий підхід лежить в площині еволюції маркетингових концепцій в торгівлі і відповідає новітнім етапам їі розвитку. Базою моделювання, запропонованою автором, є три блоку: процесний, що характеризує довгострокові умови і процеси стійкого економічного розвитку роздрібної торгівлі; функціональний, який використовує методи ресурсообміну та моделювання параметрів ефективної взаємодії учасників рітейлу; результуючий, що забезпечує раціональність і інноваційність змін об'єкта дослідження [9]. Запропоновані складові блоків в моделі поділяються на виробничотехнологічну, організаційну, економічну, маркетингову i iнфраструктурну. Дослідження O.В. Зозульова мають високу теоретичну i практичну значущість як одні 3 перших досліджень інноваційної активності вітчизняної роздрібної торгівлі. Однак внесок маркетингового управління в роботах досліджений, на наш погляд, недостатньо.

Досягнення цілей інноваційного розвитку української торгівлі обмежується як інституційними протиріччями, так і обмеженістю внутрішніх ресурсів, що визначають інноваційний потенціал [9]. Проведений аналіз статистичних показників рітейлу показує, що зростання обсягів ресурсів: фінансових (інвестиції в основний капітал), технічних (вартість основних фондів), 
матеріальних (вартість товарних запасів), кадрових (число зайнятих в торгівлі) не призводить до суттєвих зрушень в ефективності діяльності торгових компаній.

Маркетингова орієнтація інноваційного розвитку торговельних підприємств має на увазі:

1) визначення потреб ринку в нових виробах, поліпшення або модернізацію вже існуючих, таким чином задовольняє запити виробників в забезпеченні інфраструктури для розвитку інновацій;

2) пошук нових шляхів максимізації задоволеності споживачів за рахунок застосування інструментального маркетингового апарату i забезпечення інноваційного розвитку на основі нових можливостей задоволення потреб клієнтів;

3) підвищення ефективності торгової діяльності за рахунок трансформації традиційних дистриб'юторських каналів, реалізації нових способів досягнення ринкового впливу через інтеграцію, оптимізацію витрат. Інтегрований підхід до моделювання маркетингового управління базується на формуванні сукупності бізнес процесів і відповідних їм інструментів, вбудованих в загальну бізнесмодель торгового підприємства [9]. Інтегрована модель відображає бізнеспроцеси, що реалізуються на стратегічному, оперативному і тактичному рівнях, що лежать в різних площинах і напрямках діяльності підприємства.

Інтегрований підхід до формування моделі дозволяє забезпечити високу клієнтоорієнтованість компанії, наявність єдиної клієнтської бази, яка використовується як для маркетингової діяльності в продажах, так i для створення інновації, розробки інтегрованих маркетингових планів, які об'єднують всі канали продажів і комунікацій. Для забезпечення інноваційного розвитку торгівлі інтегрована модель маркетингового управління повинна будуватися 3 урахуванням маркетингових принципів інноваційного розвитку. Принципи маркетингового управління інноваційним розвитком торгівлі, що становлять основу формування моделі маркетингового управління, такі:

- максимізація задоволення потреб покупців і стейкхолдерів за рахунок реалізації користувальницьких інновацій;

- залучення персоналу в процес розробки і впровадження інновацій;

- омніканальність;

- бенчмаркінг;

- реалізація інноваційного розвитку на основі ресурсозбереження;

- принцип відповідності маркетингової моделі стратегії інноваційного розвитку підприємства.

Загальний підхід до моделювання маркетингової моделі інноваційного розвитку може бути представлений у вигляді єдності компонентів: стратегія інноваційного розвитку, методи маркетингового управління інноваційного розвитку, ресурсне забезпечення.

Стратегія визначає методи досягнення цілей, інформаційне поле дозволяє 
оперативно впроваджувати, використовувати, масштабувати і контролювати. Вся сукупність названих елементів в широкому розумінні, призводить до формування певної моделі маркетингового управління(табл.).

Особливість бізнесмоделювання, і моделювання маркетингового управління як його частини, полягає в тому, що об'єктом є бізнес-процеси. На базі досліджених публікацій доцільно визначити бізнес-процеси торгових підприємств. В основі класифікації бізнес-процесів торгової компанії може використовуватися як системний, так i традиційний підхід. Розглянемо системний підхід, згідно з яким бізнес-процеси поділяються на управлінські, підтримуючі і операційні.

Керуючі бізнес-процеси виконують функції контролю, аналізу, планування, обслуговування клієнтів. У сучасних ринкових умовах управління здійснюється за допомогою введення інноваційних моделей маркетингу i менеджменту. Підтримують бізнес-процеси забезпечують обслуговування рітейлпроцесу. Підтримка діяльності торгового підприємства здійснює відділ кадрів, бухгалтерська служба, адміністративно господарська служба та ін. Вони проводять цифрування даних, застосовують високотехнологічні інформаційні технології [10].

Таблицяя

Формування моделі маркетингового управління розвитком рітейлу

\begin{tabular}{|c|c|c|}
\hline $\begin{array}{l}\text { Стратегічний } \\
\text { напрямок } \\
\text { інноваційного } \\
\text { розвитку }\end{array}$ & $\begin{array}{c}\text { Маркетингові концепції та } \\
\text { інструменти }\end{array}$ & Результат \\
\hline Інформатизація & $\begin{array}{c}\text { Маркетинг відносин } \\
\text { Маркетинг залучень } \\
\text { Співтворчість цінностей }\end{array}$ & $\begin{array}{l}\text { Системи обліку та інвентаризації майна } \\
\text { і автоматизації складу. } \\
\text { Віртуалізація ІТ-інфраструктури рітейл } \\
\text { підприємства. Інтегровані апаратно- } \\
\text { програмні комплекси віртуалізації. } \\
\text { Серверні системи зберігання та } \\
\text { переробки даних. Інтеграція мобільних } \\
\text { пристроїв } 3 \text { корпоративною IT- } \\
\text { інфраструктурою. Мобільний офіс і } \\
\text { мобільна торгівля (Трендінг, вендинг, } \\
\text { платіжні термінали). }\end{array}$ \\
\hline Кастомізація & $\begin{array}{c}\text { Маркетинг купівельного } \\
\text { досвіду } \\
\text { Інтегрований маркетинг } \\
\text { Внутрішній маркетинг } \\
\text { Продакт менеджмент }\end{array}$ & 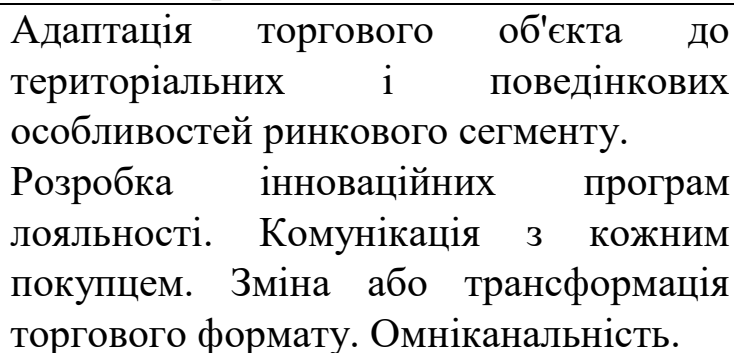 \\
\hline
\end{tabular}




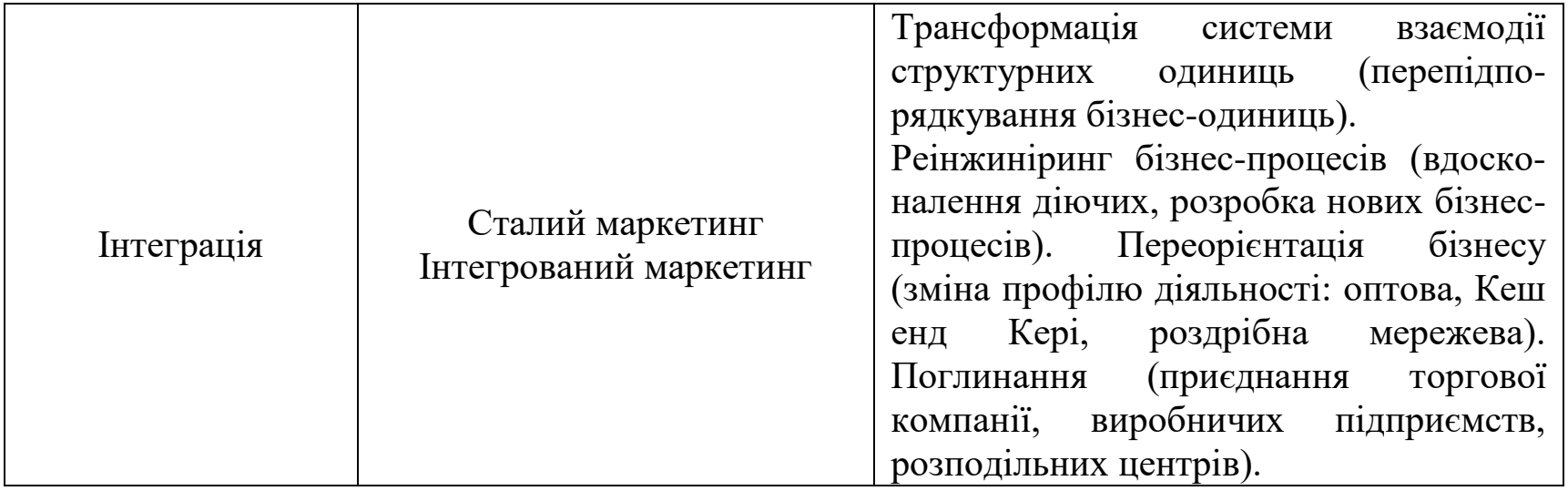

Високий рівень інтеграції маркетингової платформи дозволить досягати завдань інноваційного розвитку торгового підприємства за рахунок організаційно-управлінських ресурсів. Окреслені завдання мають ринково орієнтований характер і у сфері роздрібної торгівлі лежать у площині маркетингової концепції:

- збільшення лояльності клієнтів, зростання їх числа і середнього чека за рахунок отримання додаткової корисності, задоволення потреб інноваційним способом;

- зниження витрат за рахунок нововведень в технології продажів, зростання ефективності торгових і технологічних операцій, економія часу i ресурсів клієнтів і партнерів;

- нові шляхи розвитку торгового бізнесу, формування нових і гібридних форматів, методів продажів дозволяють торговельним підприємствам формувати конкурентні переваги на базі інновацій.

Висновки. Модель маркетингового управління інноваційним розвитком торгівлі, охоплюючи бізнес-процеси торгового підприємства всіх рівнів, дозволить досягти цілей інноваційного розвитку за рахунок можливості формування взаємовідносин рітейлових підприємств 3 виробниками $\mathrm{i}$ споживачами, внутрішнього маркетингу рітейлерів, забезпечить реалізацію інтересів усіх позначених учасників товарного обігу.

\section{Лimepamypa:}

1. Mckinsey.com (2020), "Rebooting Retail How technology will shape the future of retail 2020" available at: https://mck.co/35P93wo (Accessed December 2020)

2. Андерсен Бйорн. Бізнес процеси. Інструменти вдосконалення. / Пер. 3 англ. С.В. Арінічева / Наук. ред. Ю.П. Адлер М .: РІА «Стандарти та якість», 2003, - 272 с. іл. (Серія «Практичний менеджмент»).

3. Асоціація рітейлерів України. Офіційний сайт [Електронний ресурс]. - Режим доступу: https://rau.ua.

4. Бровченко В. А. Власні торгові марки в роздрібній торгівлі / В. А. Бровченко // Економічний вісник НТУУ «КПІ»: збірник наукових праць. - 2010. - № 7. - С. 143-148.

5. Гассман О., Франкенбергер К., Шик М. Бізнесмоделі: 55 кращих шаблонів - М .: Альпіна Паблішер, 2017. - 432 с. 
6. Федорченко А. В. Концептуальні підходи до управління лояльністю споживчів у системі холістичного маркетингу підприємства / Федорченко А. В. // Економіка та підприємництво : зб. наук. пр. / М-во освіти і науки України, ДВНЗ «Київ. нац. екон. ун-т ім. Вадима Гетьмана»; [редкол.: І. М. Рєпіна (відп. ред.) та ін.]. - Київ : КНЕУ, 2018. - № 41. - С. 69-80.

7. Данило С.I. Ефективність інновацій в роздрібній торгівлі / С.І. Данило // Соціально економічні проблеми сучасного періоду України. — 2019. — № 3 (137). -С. 50-54.

8. Зозульов О. Функціонально-структурна модель товару як основа для стрестестування маркетингової бізнес-моделі компанії / Олександр Зозульов, Тетяна Царьова // Маркетинг в Україні. - 2018. - № 3. - С. 47-54.

9. Зозульов О.В. Формування концепції ведення бізнесу на маркетингових засадах: сьогодення та майбутнє Маркетинг в Україні. - 2017. - № 5-6 - С. 64-72.

10. Мних О.Б., Кіндрат С.В. Стартап-індустрія компаній і сучасні вимоги до побудови бізнес-моделей в умовах смарт-спеціалізації. Інноваційно-інформаційні процеси у маркетингу: колективна монографія / Т. Є. Удовиченко, К. О. Дорошкевич, О. Б. Мних, С. В. Кіндрат. Дніпро: Журфонд, 2019. С.104-126.

\section{References:}

1. "Rebooting Retail How technology will shape the future of retail 2020" ["Rebooting Retail How technology will shape the future of retail 2020" ]. (n.d.) Mckinsey.com. Retrieved from https://mck.co/35P93wo [ in English].

2. Andersen Biorn (2003). Biznes protsesy. Instrumenty vdoskonalennia [Business processes. Improvement tools.]. ( S.V. Arinicheva, Trans, Yu.P. Adler (Ed.). Moscow: RIA «Standarty ta yakist» [in Russian].

3. Site Asotsiatsii riteileriv Ukrainy [site of the Association of Retailers of Ukraine]. rau.ua. Retrieved from https://rau.ua [in Ukrainian].

4. Brovchenko, V.A. (2010). Vlasni torhovi marky v rozdribnii torhivli [Private labels in retail]. Ekonomichnyi visnyk NTUU «KPI»- Economic Bulletin of NTU «KPI», 7, 143-148 [in Ukrainian].

5. Gassmann O., Frankenberger K., Csik M.(2017). Biznesmodeli: 55 krashchykh shabloniv [The Business Models: 55 best templates]. Moscow: Alpina Pablisher [in Engish].

6. Fedorchenko A. V.(2018). Kontseptualni pidkhody do upravlinnia loialnistiu spozhyvchiv u systemi kholistychnoho marketynhu pidpryiemstva [Conceptual approaches to consumer loyalty management in the system of holistic marketing of the enterprise]. I. M. Riepina (Eds.), Ekonomika ta pidpryiemnytstvo - Economics and entrepreneurship. Proceedings M-vo osvity i nauky Ukrainy, DVNZ «Kyiv. nats. ekon. un-t im. Vadyma Hetmana» (pp. 69-80). Kyiv : KNEU [in Ukrainian].

7. Danylo, S. I. (2019). Efektyvnist' innovatsiy v rozdribniy torhivli [Efficiency of innovations in retail trade]. Sotsial'no-ekonomichni problemy suchasnoho periodu Ukrayiny - Socio-Economic Problems of the Modern Period of Ukraine, 137 (3), 50-53 [in Ukrainian].

8. Zozulov O. \& Tsarova T. Funktsionalno-strukturna model tovaru yak osnova dlia strestestuvannia marketynhovoi biznes-modeli kompanii [Functional-Structural Model of the Goods as a Basis for Stress-Testing of a Marketing Business Model of a Company]. Marketynh v Ukraini - marketing in Ukraine, 3, 47-54 [in Ukrainian].

9. Zozulov O.V.( 2017) Formuvannia kontseptsii vedennia biznesu na marketynhovykh zasadakh: sohodennia ta maibutnie [Forming the concept of doing business on a marketing basis: present and future]. Marketynh v Ukraini - marketing in Ukraine,. 5-6, 64-72 [in Ukrainian].

10. Mnykh O.B., Kindrat S.V., Udovychenko T. Ye., Doroshkevych K. O., (2019)Startapindustriya kompaniy i suchasnivymohy do pobudovy biznes-modeley vumovakh smartspetsializatsiyi:monohrafiya[Startup industry of companies and modernrequirements for building business models in the conditions of smart specialization]. Dnipro: Zhurfond [in Ukrainian]. 